\title{
Bioengineered models to study tumor dormancy
}

\author{
Shreyas S. Rao ${ }^{*}$ D, Raghu Vamsi Kondapaneni and Akshay A. Narkhede
}

\begin{abstract}
The onset of cancer metastasis is the defining event in cancer progression when the disease is considered lethal. The ability of metastatic cancer cells to stay dormant for extended time periods and reawaken at later stages leading to disease recurrence makes treatment of metastatic disease extremely challenging. The tumor microenvironment plays a critical role in deciding the ultimate fate of tumor cells, yet the mechanisms by which this occurs, including dormancy, is not well understood. This mini-review discusses bioengineered models inspired from tissue engineering strategies that mimic key aspects of the tumor microenvironment to study tumor dormancy. These models include biomaterial based three dimensional models, microfluidic based models, as well as bioreactor based models that incorporate relevant microenvironmental components such as extracellular matrix molecules, niche cells, or their combination to study microenvironmental regulation of tumor dormancy. Such biomimetic models provide suitable platforms to investigate the dormant niche, including cues that drive the dormant to proliferative transition in cancer cells. In addition, the potential of such model systems to advance research in the field of tumor dormancy is discussed.
\end{abstract}

Keywords: Tumor dormancy, Tumor microenvironment, Metastasis, Bioengineered models

\section{Introduction}

The progression of cancer from the primary to the metastatic setting usually marks the transition to an incurable diagnosis [1]. Accumulating evidence suggests that disseminated tumor cells can stay in a dormant state for extended periods of time and could reawaken at a later stage resulting in disease relapse and often mortality [2]. For instance, greater than $67 \%$ of deaths from breast cancer occur beyond the 5-year survival window and disease recurrence is noted after almost a decade of being "cancer-free" in many patients $[3,4]$. In addition, dormant tumor cells can also persist at the primary tumor site, following surgical resection of the primary tumor [5]. Tumor cells can also metastasize and stay dormant even prior to the evolution of the primary tumor [6]. While drug treatments exist, resistance to treatment is noted in many patients and the dormant/ resistant tumor cells surviving treatment reactivate and contribute to disease progression at the primary and/or metastatic site [7] (i.e., in organs such as bone, liver, lung,

\footnotetext{
* Correspondence: srao3@eng.ua.edu

Department of Chemical and Biological Engineering, The University of Alabama, Tuscaloosa, AL 35487-0203, USA
}

and the brain). These observations highlight the need to understand the cellular and molecular mechanisms associated with tumor cell dormancy.

It is now well appreciated that the tumor microenvironment plays a significant role in controlling the dormant phenotype in tumor cells in addition to genetic alterations $[2,8-10]$. In the context of metastatic disease, this is consistent with Paget's "seed and soil" hypothesis proposed over a century ago, which states that metastasis occurs only when the organ environment (soil) is conducive to metastatic tumor cell (seed) growth [11-14]. Thus, experimental models to study and understand the mechanisms associated with dormancy must capture the bidirectional tumor cell-microenvironment interactions. In early work elucidating the role of microenvironment on tumor dormancy, Aguirre-Ghiso and colleagues showed that growth signals from fibronectin (an extracellular matrix (ECM) protein) via the urokinase plasminogen activator receptor (uPAR)- $\alpha_{5} \beta_{1}$-integrin complex was critical, and thus reduction in the level of uPAR in human epidermoid cancer cells induced tumor dormancy when tested using standard tissue culture polystyrene (TCPS) substrates (routinely employed two dimensional (2D) culture models) in vitro

(c) The Author(s). 2019 Open Access This article is distributed under the terms of the Creative Commons Attribution 4.0 International License (http://creativecommons.org/licenses/by/4.0/), which permits unrestricted use, distribution, and 
as well as using mouse models in vivo [15]. Studies utilizing these models have also defined several key molecular features of tumor cell dormancy, including a high signaling ratio of p38/ERK [16-19].

A variety of in vivo mouse models, including genetically engineered mouse models, orthotropic /subcutaneous tumor models, tumor resection models, as well as experimental metastasis mouse models have been used to gain insight into tumor dormancy [20-23]. For instance, experimental metastasis mouse models have revealed the existence of a dormant state in cancer cells delivered to a metastatic organ site in vivo [24, 25]. However, mouse models provide limited control of the organ environment for controlled investigations. In addition, animal-animal variations, difficulties associated with imaging dormant cells in internal tissues, as well as high costs, can make the use of such models a challenging undertaking. In recent years, there has been a growing interest in utilizing components typically employed in tissue engineering (e.g., biomaterial scaffolds, tissue specific cells, and bioreactors) to study the tumor microenvironment and its role in governing tumor dormancy. These systems not only enable better recapitulation of the tumor microenvironment by capturing the relevant microenvironmental cues such as biophysical cues compared to the traditionally studied 2D culture models but also the study of tumor cell phenotype in a physiological relevant and controlled setting.

This review focuses on various tissue engineering inspired strategies that have been employed to elucidate microenvironmental regulation of tumor cell dormancy. In particular, we discuss biomaterial based models, microfluidic based models, as well as bioreactor based models and how these bioengineered models have been utilized to study the dormant phenotype as well as the transition from a dormant to proliferative phenotype in cancer cells. Collectively, such microenvironment mimicking model systems provide useful tools to probe the dormant niche as well as elucidate the molecular mechanisms regulating tumor dormancy.

\section{Bioengineered models mimicking the tumor microenvironment to study tumor cell dormancy Biomaterial based models}

Biomaterial scaffolds commonly employed in tissue engineering such as hydrogels, porous scaffolds, and electrospun fibrous scaffolds have been used as models to study tumor cell dormancy. Such three dimensional (3D) culture systems could be engineered to mimic specific features of the tumor microenvironment (e.g., stiffness, topography) as well as incorporate other relevant noncancerous cells. In this section, we discuss the various types of biomaterial based models that have been employed to study microenvironmental regulation of tumor dormancy.

\section{Natural biomaterial based models}

A variety of natural biomaterials have been used to study tumor cell dormancy and maintenance of this state via targeting the cytoskeletal organization [26], incorporating relevant niche cells $[27,28]$, modulation of stiffness [29], or via modulation of signaling pathways (e.g., Src family kinase (SFK) inhibition [30]). Specifically, hydrogels composed of Collagen-I [31], hyaluronic acid [32], fibrin [29], and Matrigel [26, 30, 31, 33] have been employed (studies summarized in Table 1). Barkan et al., utilized Basement Membrane Matrix (BME) (or Matrigel) and found that this matrix maintained the dormant state of D2.0R cancer cells that were observed to be dormant in vivo as opposed to traditionally studied $2 \mathrm{D}$ models (e.g., TCPS) and that the transition to the proliferative state was mediated via $\beta-1$ integrin signaling [26]. Further, myosin light chain kinase (MLCK) activation was also necessary for this transition as inhibition of MLCK or $\beta-1$ integrin impeded the dormant to proliferative state transition. Similarly, A549 lung cancer cells cultured in Matrigel underwent dormancy and exhibited drug resistance compared to standard 2D culture (TCPS) [34].

In contrast to BME inducing a dormant state, incorporating Collagen-I within BME lead to a proliferative phenotype in dormant mouse breast cancer D2.0R cells in vitro [35]. Activation of $\beta-1$ integrin was responsible for the emergence of this phenotype and thus inhibiting $\beta-1$ integrin and the associated downstream signaling pathway components (Src, extracellular-signal regulated kinase (ERK), or MLCK) significantly inhibited proliferation. Modulation of signaling pathways to control the dormant vs. proliferative phenotype has also been investigated using natural biomaterial based models. Specifically, SFK inhibition caused localization of p27 (cyclin dependent kinase inhibitor) to the nucleus and inhibited proliferation that was induced by incorporating Collagen-I into BME [30]. Further, combined targeting of SFK and mitogen activated protein kinase (MEK) was shown to induce apoptosis in dormant cancer cells, thereby demonstrating the efficacy and potential of this combinatorial treatment for treating recurrent disease.

Niche cells present in the tumor microenvironment have been incorporated into natural biomaterial scaffolds to create a model of dormancy for bone metastatic breast cancer cells. For example, Marlow et al., employed a 3D collagen biomatrix that were seeded with either primary bone marrow stromal cells (BMSC) or a mix of osteoblasts, mesenchymal, and endothelial cell lines (BMCL-Bone marrow cell lines) [27]. In this system, breast cancer cells co-cultured with BMSCs 


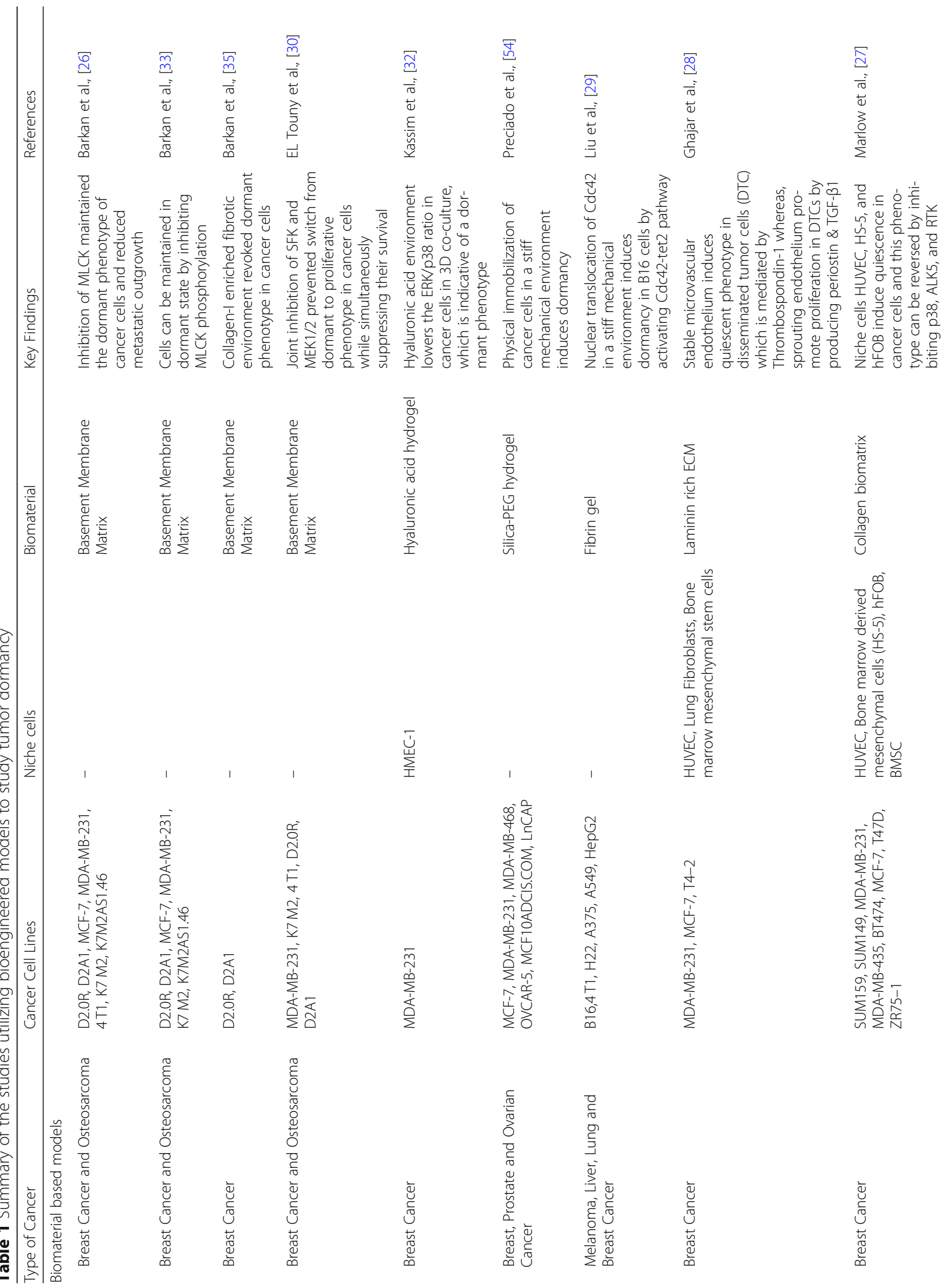




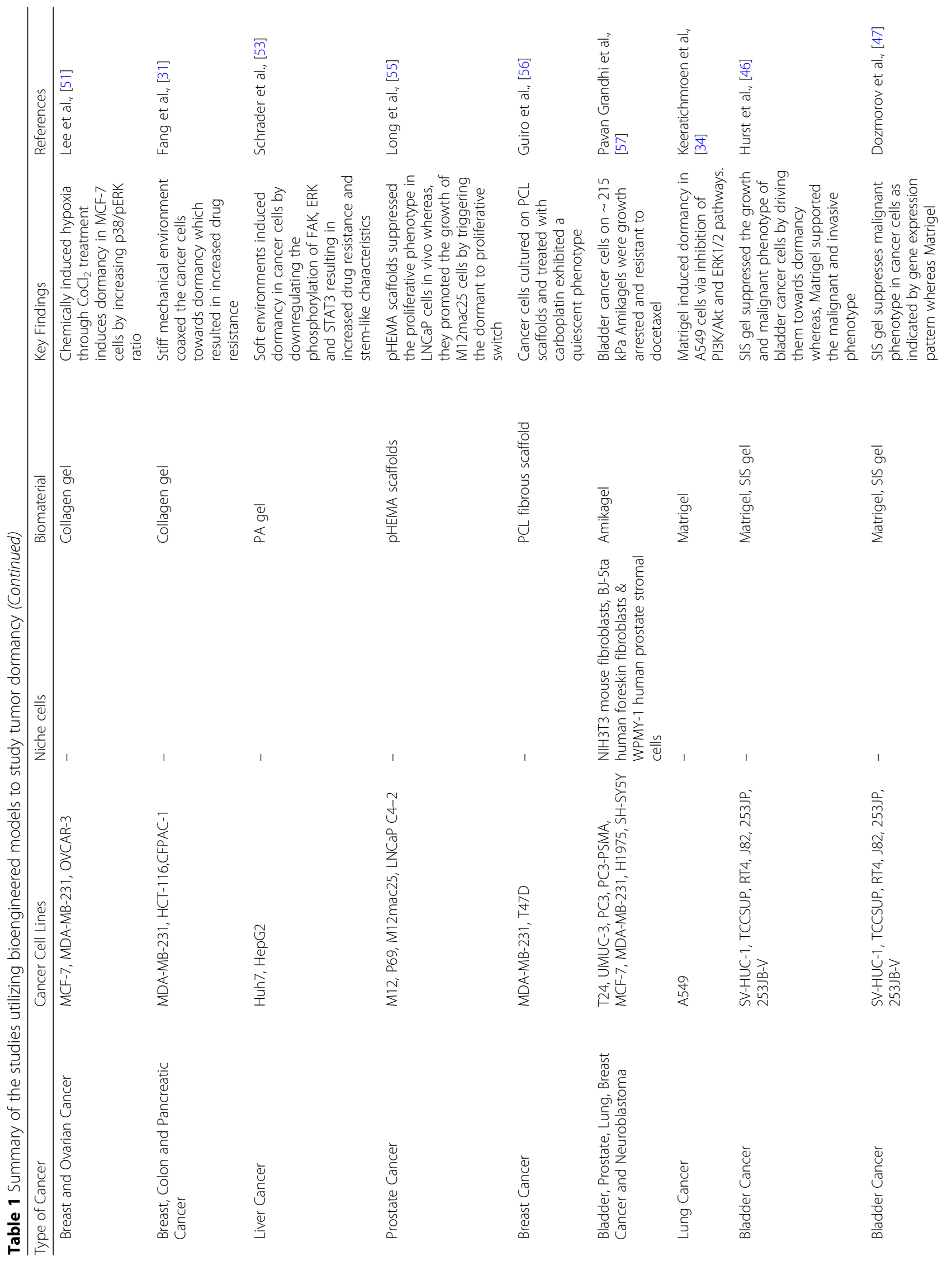




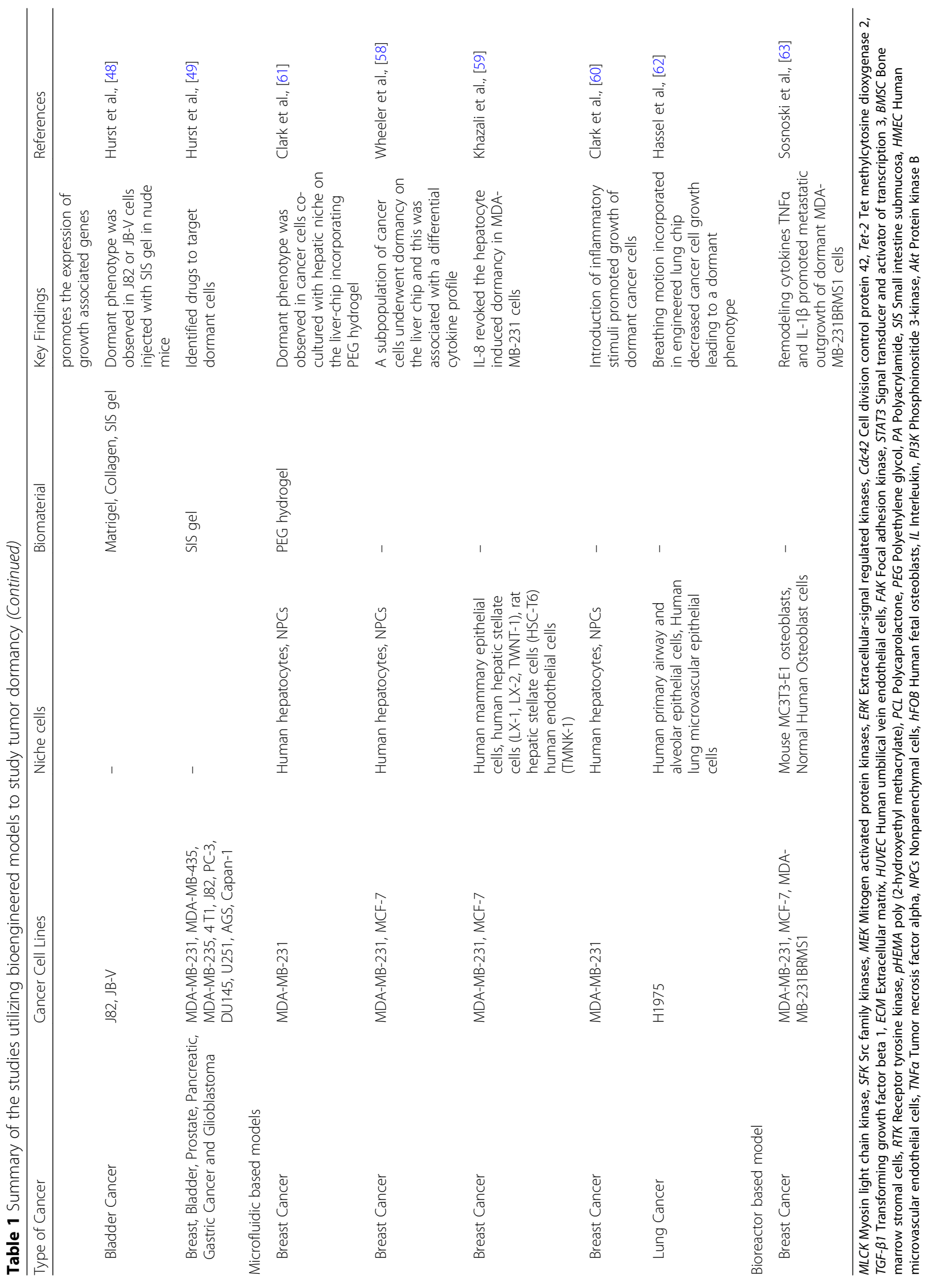


proliferated whereas those cultured with BMCL remained in a dormant state and this phenomenon was observed both in vitro and in vivo. Moreover, breast cancer cells retrieved from BMCL co-cultures began proliferating when co-cultured with BMSCs. The dormant state observed in this model was also reversible when $\mathrm{p} 38$, and receptor tyrosine kinase (RTK) (pathways involved in dormancy [36-38]) was inhibited. These observations were also validated in vivo by subcutaneously implanting cell-laden biomaterial constructs in murine models. Such "hybrid in vivo models" wherein biomaterial scaffolds are integrated with murine models have been recently utilized in several investigations to study the metastatic niche [39-45]. Similarly, Ghajar et al., demonstrated that endothelial cells influenced the dormant phenotype in breast cancer cells in a laminin-rich ECM [28]. Specifically, established or stable endothelium induced a dormant state via endothelial-derived thrombospondin-1 (TSP-1). In contrast, the authors showed that cancer cell growth was accelerated at sprouting neovascular tips (i.e., sprouting endothelium), which was associated with enhanced expression of Transforming growth factor beta 1 (TGF- $\beta 1$ ) and periostin, and with the loss of TSP-1. In a hyaluronic acid hydrogel model, when breast cancer cells were co-cultured with a human microvascular endothelial cell line (HMEC-1), expression of ERK/p38 was reduced in co-culture compared to breast cancer cell monoculture indicating the emergence of a dormant state in breast cancer cells [32].

Similar to the utilization of Matrigel, Hurst et al., [46] utilized SIS gel (derived from small intestine submucosa (SIS) representative of a normal basement membrane matrix) to study phenotype regulation in bladder cancer cells and compared it with Matrigel (representative of a remodeled tumor matrix). In these studies, Matrigel promoted a more invasive phenotype as opposed to a non-aggressive phenotype that was observed in the SIS gel. Further, cells isolated from Matrigel when grown on SIS gel demonstrated growth characteristics similar to cells grown on SIS gel and vice versa demonstrating that this phenotype regulation was dependent on the gel composition. These results were further supported via comparative gene expression studies [47]. In a follow up study, these observations were further validated using hybrid in vivo models [48]. In particular, when J82 or JB-V bladder cancer cells were subcutaneously injected with SIS gel in nude mice, cancer cells were observed to be in a dormant state with no sign of tumor formation. However, in some cases, cells transitioned from a dormant to a proliferative state. Tumor growth was noted in $40 \%$ of SIS gel xenografts following a 4-18 week dormancy period. Specifically, the transition from a dormant to a proliferative phenotype was dependent on the number of implanted tumor cells, with tumors more likely to form when more than 3 million tumor cells were implanted [48]. These models have also been utilized to identify therapeutics that target dormant cells [49] .

Hypoxia, a characteristic feature of the tumor microenvironment [50], has also been incorporated with natural biomaterials such as Collagen to develop dormancy models. For example, Lee et al., utilized cobalt chloride $\left(\mathrm{CoCl}_{2}\right)$ (a hypoxia mimicking agent) with Collagen gels to induce dormancy in breast cancer cells [51]. They found that MCF-7 breast cancer cells exhibited a dormant phenotype in this model system and this phenotype was reversible when the cells were grown in $\mathrm{CoCl}_{2}$ free media. These results were also observed when the cells were grown on non-adhesive poly(2-hydroxyethyl methacrylate) (pHEMA) coated tissue culture plates (Fig. 1).

More recently, fibrin gels were employed to elucidate the impact of matrix stiffness on tumor cell dormancy. Specifically, Liu et al., employed [29] fibrin gels of 90,

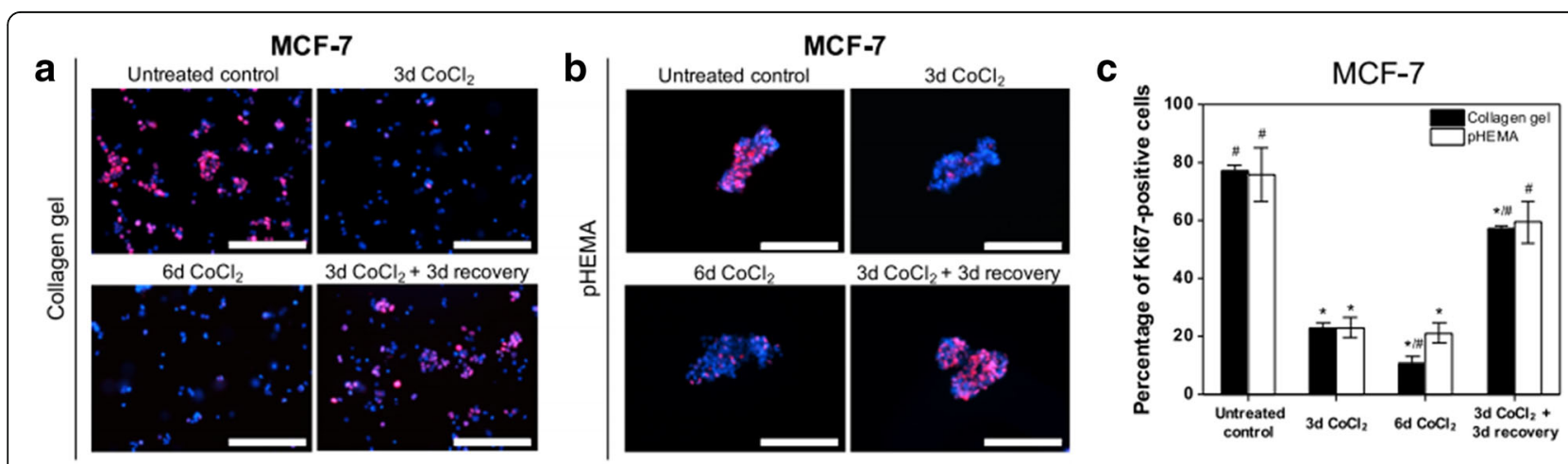

Fig. 1 In a Collagen hydrogel incorporating hypoxia mimicking agent $\mathrm{CoCl}_{2}(300 \mu \mathrm{M})$ or pHEMA coated culture plates, MCF7 breast cancer cells exhibited a dormant phenotype, which was reversible after treatment with $\mathrm{CoCl}_{2}$ free growth media. Fluorescence images of MCF7 cells stained for Ki67 (red) and nuclei (blue) for untreated control, 3 day treatment with $\mathrm{CoCl}_{2}, 6$ day treatment with $\mathrm{CoCl}_{2}$ and 3 day treatment with $\mathrm{CoCl} 2$ followed by 3 day recovery period in (a) Collagen hydrogels and (b) pHEMA coated culture plates and (c) quantification of Ki-67 status in these conditions. Scale bar $=200 \mu \mathrm{m}$. Figure taken from [51] and reprinted with permission of BioMed Central (Springer Nature) 
450 and $1050 \mathrm{~Pa}$ bracketing the range of stiffness noted for many tissues (100-3000 Pa [52]). In this system, murine B16 \& human melanoma A375 cells embedded within $1050 \mathrm{~Pa}$ fibrin gels remained dormant as opposed to those in $90 \mathrm{~Pa}$ gels. This induced dormancy was reversible, as cells isolated from $1050 \mathrm{~Pa}$ fibrin gel proliferated when cultured in $90 \mathrm{~Pa}$ gels. Maintenance of the dormant state with increasing stiffness in this system was mediated via translocation of cell division control protein 42 (Cdc42) from the cytosol to the nucleus, in turn, promoting tet methylcytosine dioxygenase 2 (Tet-2) expression, and subsequently activating cell-cycle inhibiting p21 and p27 genes.

\section{Synthetic biomaterial based models}

In addition to natural biomaterial-based models, synthetic biomaterial systems such as polyacrylamide (PA), silicapolyethylene glycol (silica-PEG), polycaprolactone (PCL), and pHEMA have been utilized to study the impact of tumor microenvironment on the dormant phenotype. Synthetic biomaterials provide a highly tunable platform and are more reproducible compared to natural biomaterial-based models. Schrader and colleagues utilized PA hydrogels to study the influence of matrix stiffness on the behavior of hepatocellular carcinoma cells [53]. They found these cancer cells cultured on stiff hydrogels $(12 \mathrm{kPa})$ rapidly proliferated compared to soft hydrogels $(1 \mathrm{kPa})$ as indicated via increased Ki67 (a proliferation marker) positivity, with the soft hydrogels promoting a more dormant-like phenotype. Inhibition of $\beta 1$-integrin or Focal adhesion kinase (FAK) significantly reduced Ki-67 status on stiff hydrogels $(12 \mathrm{kPa})$, thereby implicating these pathways in the observed cellular response.

Physical immobilization of cancer cells in synthetic biomaterials has also been shown to induce a dormant phenotype in cancer cells. For instance, MCF-7 breast cancer cells encapsulated in a porous silica-PEG hydrogel system underwent cell-cycle arrest, but resumed proliferation when they were retrieved from the hydrogel and cultured on TCPS [54]. Similarly, Long et al., employed sphere-templated porous pHEMA hydrogels to develop prostate cancer xenografts [55]. Using this system, they demonstrated that M12mac25 prostate cancer cells subcutaneously inoculated into athymic nude mice using Matrigel stayed largely dormant. However, with pHEMA scaffolds (with or without Matrigel) tumor formation was noted providing a model of dormancy escape in prostate cancer cells.

In addition to hydrogels, synthetic electrospun fiberbased biomaterials have been used to study tumor dormancy. To this end, random or aligned electrospun PCL fibrous scaffolds were used to examine the behavior of Carboplatin (a chemotherapy) treated vs. non treated breast cancer cells [56]. Non treated breast cancer cells exhibited a more dormant phenotype on fibrous scaffolds as evidenced using cell cycle analysis whereas the treated breast cancer cells exhibited this phenotype when cultured on fibrous scaffolds as well as TCPS.

\section{Semi-synthetic biomaterial based models}

Semi-synthetic scaffolds fabricated using a combination of natural and synthetic materials have also been investigated to develop models of tumor dormancy. For example, Pavan Grandhi et al., utilized amikacin hydrate and poly (ethylene glycol) diglycidyl ether (PEGDE) to develop a new hydrogel termed as "Amikagel" that was used to study dormancy in bladder cancer [57]. They found that $90 \%$ of T24 bladder cancer cells cultured on $\sim 215 \mathrm{kPa}$ Amikagels were cell cycle arrested in G0/G1 phase and were resistant to chemotherapeutic drugs such as docetaxel. However, when cells from the $\sim 215$ $\mathrm{kPa}$ Amikagels were transferred to $\sim 36 \mathrm{kPa}$ Amikagels, a sub-population of cells escaped dormancy and began proliferating. Overall, such biomimetic biomaterial based models provide useful tools to better understand the dormant niche. For instance, biomaterial based models are well suited to probe the impact of biophysical cues (such as matrix stiffness) on tumor dormancy versus traditional 2D culture models. These tools would also subsequently allow the study of molecular mechanisms governing the dormant phenotype as well as the dormant-to-proliferative switch.

\section{Microfluidic based models}

Microfluidic based models have also been used to study tumor dormancy. Such models allow for incorporation of nutrient/growth factor gradients. In addition, niche cells present in the tumor microenvironment are also typically incorporated in these models. One of the microfluidic based models is the commercially available LiverChip ${ }^{\circ}$ wherein hepatocytes and non-parenchymal cells (NPCs) can be co-cultured to form an ex vivo microphysiologic model of the liver that could be used to study dormancy in cancer cells, including those that metastasize to the liver [58]. In this system, hepatocytes can be cultured for $\sim 15$ days without losing their functionality. This setup also contains an oxygen sensor and micro-reactor pumps to control the flow of nutrients and growth factors. In this system, a sub population of MDA-MB-231 and MCF7 breast cancer cells underwent dormancy (Fig. 2) that was associated with an increase in cancer attenuation signals (i.e., follistatin) and decrease in the pro-inflammatory signals (Insulin like growth factor binding protein 1 (IGFBP-1), Macrophage inflammatory protein 1 alpha (MIP-1 $\alpha)$, Monocyte chemoattractant protein (MCP-1) \& Interleukin-6 (IL-6)) for MDA-MB-231 


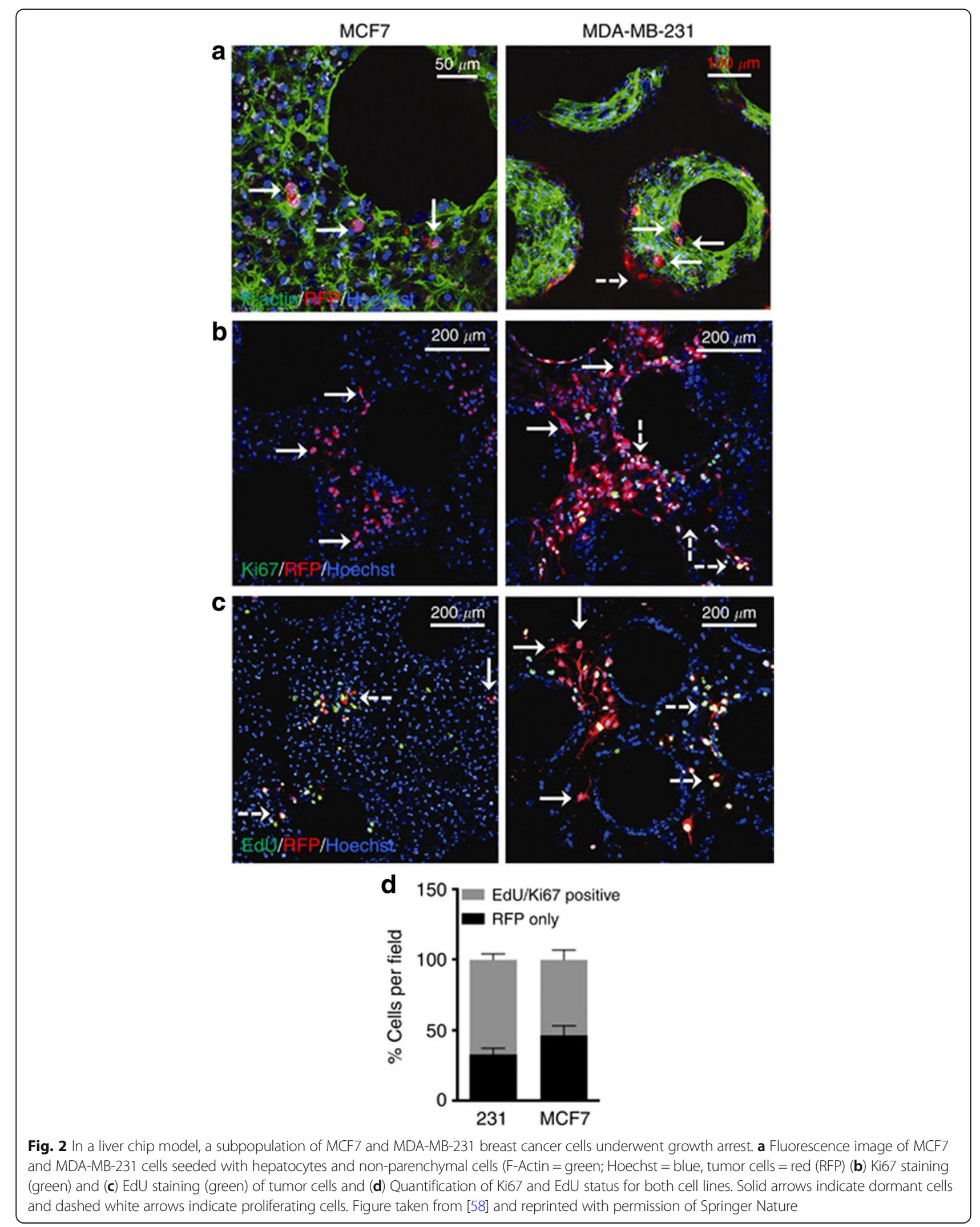


cells, whereas in the case of MCF-7 cells, increase in cancer associated (e.g., Vascular endothelial growth factor A (VEGF-A), Epidermal growth factor (EGF)) and pro-inflammatory signals (IL-6, MCP-1) was noted. More recently, Khazali et al., tested if inflammatory signals present in the hepatic niche (from hepatic stellate cells) stimulated escape from the dormancy phenotype using the LiverChip [59]. Indeed, introduction of IL-8 promoted proliferation of otherwise dormant MDA-MB231 breast cancer cells as tested using EdU incorporation assay. This was also associated with an increase in phosphorylated ERK levels. Similarly, Clark et al., demonstrated that introduction of an inflammatory stimuli such as EGF or lipopolysaccharide (LPS) promoted proliferation of dormant MDA-MB-231 breast cancer cells [60].

Biomaterial scaffolds have also been incorporated into microfluidic based models for studies of tumor dormancy. For example, a PEG based hydrogel was incorporated into the liver microphysiological system by Clark et al., in a follow up study [61]. In this model, MDA-MB-231 breast cancer cells exhibited a dormant phenotype on the PEG based hydrogel as compared to the polystyrene. Further, these cells were also found to be resistant to high doses of chemotherapy drugs such as Cisplatin and Doxorubicin on the hydrogel as opposed to polystyrene supported cultures.

In addition to breast cancer, microfluidics based models have been employed to study dormancy versus growth in lung cancer. A lung cancer-on-a-chip, specifically, lung airway chip and lung alveolus chip, was developed by Hassell and colleagues utilizing microfluidics [62]. Both chips utilize a two channel microfluidic set-up separated via a porous membrane coated with ECM proteins and incorporate airway or lung alveolar epithelial cells interfaced with endothelial cells. In this model, they found that non-small-cell lung cancer cells stayed relatively dormant in the lung airway chip as opposed to the lung alveolus chip wherein significant growth was observed.

\section{Bioreactor based models}

In addition to biomaterial and microfluidic based models, bioreactor based models have been used to investigate dormancy. Niche cells are also incorporated in such models as they allow long term culture. Such a model was utilized by Sosnoski et al. [63], to study breast cancer cell dormancy in a bone mimetic environment as breast cancer cells are known to metastasize to the bone $[64,65]$. In this model, a bioreactor was employed to culture bone cells (murine MC3T3-E1 and human osteoblast cells) for up to 120 days. During this culture period, osteoblasts generated tissue that contained 6 or more layers of cells mimicking the pericellular environment [66]. Two month old bioreactor cultures were employed to which cytokines involved in bone remodeling were added, followed by addition of breast cancer cells. Specifically, a metastasis-suppressed MDA-MB-231BRMS1 human breast cancer cell line was used. Addition of cytokines tumor necrosis factor alpha (TNF $\alpha)$ and IL-1 $\beta$ to the bioreactor co-cultures allowed these cells to grow, which otherwise were largely growth arrested. This behavior was also seen when prostaglandin E2 (PGE2) was added to the cultures and addition of PGE2 receptor inhibitor suppressed tumor cell proliferation as seen via Ki67 staining (Fig. 3). The authors also observed a significant enhancement in focal adhesion kinase plaque formation in cancer cells in TNF $\alpha$ and IL-1 $\beta$ treated bioreactor co-cultures. While only few studies have utilized bioreactor based platforms, such platforms provide a better in vitro model system for co-culturing cancer cells as well as niche cells (e.g., breast cancer cells and osteoblasts) for longer time periods. This is advantageous as cancer cells typically stay dormant for extended periods of time in vivo and such models could be employed to capture these characteristic features.

\section{Conclusions and perspectives}

To elucidate the mechanisms governing dormancy, bioengineered models such as biomaterials, microfluidics, and

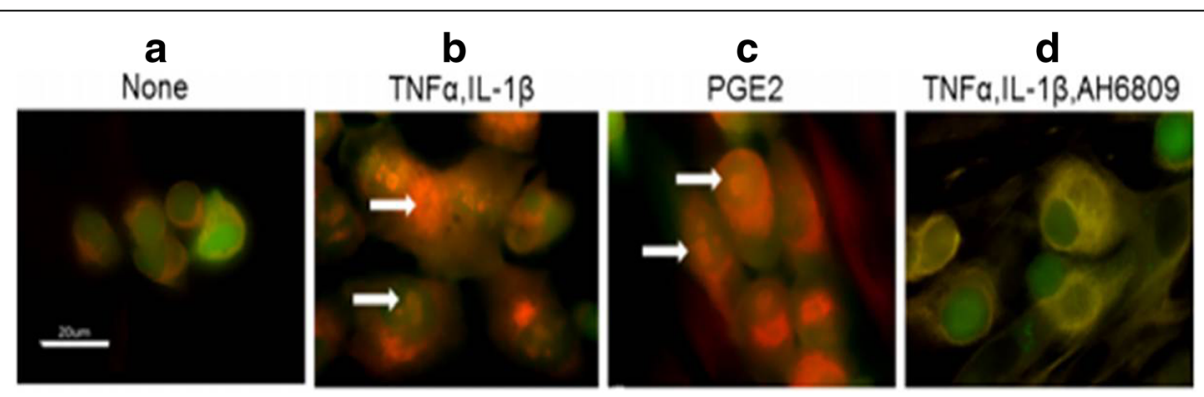

Fig. 3 In a bioreactor model, addition of TNFa and IL- $\beta 1$ or PGE2 enabled proliferation of MDA-MB-231BRMS1 cells that were otherwise growth arrested as indicated via Ki67 staining. Fluorescence images of cells stained for Ki67 in (a) untreated control, (b) TNFa and IL- $\beta 1$ treatment, (c) PGE2 treatment, and (d) TNFa, IL-1 $\beta$ and AH6809 (PGE2 receptor inhibitor) treatment conditions. White arrows indicate positive nuclear Ki67 staining. Scale bar $=20 \mu \mathrm{m}$. Figure taken from [63] and reprinted with permission of Springer Nature 
bioreactor- based models are being increasingly utilized as biomimetic in vitro culture systems to model tumor dormancy. Unlike in vivo models, bioengineered models highlighted herein allow us to pursue a reductionist approach and thereby study how individual microenvironmental cues regulate dormancy in cancer cells owing to their versatility and tunability. To this end, these models have been largely utilized to investigate the impact of mechanical cues, biochemical cues, as well as cellular cues on tumor cell dormancy. Specifically, the cellular cues incorporated in current models largely consist of stromal and vascular cells. However, in addition to stromal and vascular cells, immune cells play a key role in cancer progression and metastasis [67-69]. Future studies should aim at incorporating immune cells such as macrophages in bioengineered models for studying immune-mediated dormancy. Further, 3D in vitro models have recently been utilized to study the microenvironmental regulation of stem-like phenotype in cancer cells [70]. There are striking parallels between cancer stem-like cells (CSCs) and dormant cancer cells. For instance, CSCs exhibit behaviors similar to dormant cancer cells such as increased drug resistance and the ability to repopulate the tumor mass in response to certain microenvironmental cues [71]. However, it is not clear whether they belong to the same dormant population or consist of a distinct population. Bioengineered models could be employed to clarify the extent of overlap between the cancer stem-like phenotype and the dormant phenotype. In addition, these models could be utilized to study the role of fundamental biological processes such as epithelial-to-mesenchymal transition and mesenchymal-to-epithelial transition in regulating cancer cell dormancy as they are known to be involved in cancer metastasis [72, 73]. Finally, current bioengineered models largely focus on single cell (cellular) dormancy, however, balance between proliferation and apoptosis could also lead to tumor dormancy (also called tumor mass dormancy) [2, 74]. It would be worthwhile to model these mechanisms in vitro using biomimetic culture systems as it will further our understanding of tumor mass dormancy. Overall, in the short term, bioengineered models could provide key scientific insight into microenvironmental regulation of the dormant phenotype and, in the long term, may enable the development of therapeutic strategies targeting dormant or active metastatic disease.

\footnotetext{
Abbreviations

Akt: Protein kinase B; BMCL: Bone marrow cell lines; BME: Basement membrane matrix; BMSC: Bone marrow stromal cells; Cdc42: Cell division control protein 42; CSCs: Cancer stem cells; ECM: Extracellular matrix; EGF: Epidermal growth factor; ERK: Extracellular-signal regulated kinase; FAK: Focal adhesion kinase; hFOB: Human fetal osteoblasts; HMEC: Human microvascular endothelial cells; HUVEC: Human umbilical vein endothelial cells; IGFBP-1: Insulin like growth factor binding protein 1; IL: Interleukin; ILK: Integrin linked kinase; LPS: Lipopolysaccharide; MCP-1: Monocyte chemoattractant protein 1; MEK: Mitogen-activated protein kinase; MIP1a: Macrophage inflammatory protein 1 alpha; MLCK: Myosin light chain
}

kinase; NPCs: Nonparenchymal cells; PA: Polyacrylamide; PCL: Polycaprolactone; PEG: Polyethylene glycol; PEGDE: Poly (ethylene glycol) diglycidyl ether; PGE2: Prostaglandin E2; pHEMA: poly (2-hydroxyethyl methacrylate); PI3K: Phosphoinositide 3-kinase; RTK: Receptor tyrosine kinase; SFK: Src family kinases; SIS: Small intestine submucosa; STAT3: Signal transducer and activator of transcription 3; TCPS: Tissue culture polystyrene; Tet-2: tet methylcytosine dioxygenase $2 ;$ TGF- $\beta 1$ : Transforming growth factor beta 1; TNFa: Tumor necrosis factor alpha; TSP-1: Thrombospondin-1; UPAR: Urokinase plasminogen activator receptor; VEGF-A: Vascular endothelial growth factor $\mathrm{A}$

\section{Acknowledgements}

Not applicable.

\section{Funding}

This work was supported by the National Science Foundation (CBET 1749837 to S.R.), The University of Alabama Graduate Council Fellowship (to R.K.), and an Alabama EPSCoR Graduate Research Fellowship (to A.N.)

\section{Availability of data and materials}

Data sharing is not applicable to this article as no datasets were generated or analyzed during the current study.

\section{Authors' contributions}

SR, RK, and AN wrote and edited the manuscript. All authors read and approved the final manuscript.

\section{Ethics approval and consent to participate}

Not applicable.

\section{Consent for publication}

Not applicable.

\section{Competing interests}

The authors declare that they have no competing interests.

\section{Publisher's Note}

Springer Nature remains neutral with regard to jurisdictional claims in published maps and institutional affiliations.

Received: 22 October 2018 Accepted: 27 December 2018

Published online: 10 January 2019

\section{References}

1. Aguado BA, Bushnell GG, Rao SS, Jeruss JS, Shea LD. Engineering the pre-metastatic niche. Nat Biomed Eng. 2017;1:0077.

2. Aguirre-Ghiso JA. Models, mechanisms and clinical evidence for cancer dormancy. Nat Rev Cancer. 2007:7(11):834-46.

3. Aguirre-Ghiso JA, Bragado P, Sosa MS. Metastasis awakening: targeting dormant cancer. Nat Med. 2013;19(3):276-7.

4. Klein CA. Framework models of tumor dormancy from patient-derived observations. Curr Opin Genet Dev. 2011;21(1):42-9.

5. Kottke T, Boisgerault N, Diaz RM, Donnelly O, Rommelfanger-Konkol D, Pulido J, et al. Detecting and targeting tumor relapse by its resistance to innate effectors at early recurrence. Nat Med. 2013;19(12):1625-31.

6. Harper KL, Sosa MS, Entenberg D, Hosseini H, Cheung JF, Nobre R, et al. Mechanism of early dissemination and metastasis in Her2+ mammary cancer. Nature. 2016;540:588.

7. Wells A, Griffith L, Wells JZ, Taylor DP. The dormancy dilemma: quiescence versus balanced proliferation. Cancer Res. 2013;73(13):3811-6.

8. Ghajar CM. Metastasis prevention by targeting the dormant niche. Nat Rev Cancer. 2015;15(4):238-47.

9. Linde N, Fluegen G, Aguirre-Ghiso JA. The relationship between dormant Cancer cells and their microenvironment. Adv Cancer Res. 2016;132:45-71.

10. Aguirre-Ghiso JA, Sosa MS. Emerging topics on disseminated Cancer cell dormancy and the paradigm of metastasis. Annual Rev Cancer Biol. 2018; 2(1):377-93

11. Paget $\mathrm{S}$. The distribution of secondary growths in cancer of the breast. Lancet. 1889;133(3421):571-3.

12. Fidler IJ. The pathogenesis of cancer metastasis: the 'seed and soil' hypothesis revisited. Nat Rev Cancer. 2003;3(6):453-8. 
13. Kaplan RN, Riba RD, Zacharoulis S, Bramley AH, Vincent L, Costa C, et al. VEGFR1-positive haematopoietic bone marrow progenitors initiate the premetastatic niche. Nature. 2005;438(7069):820-7.

14. Kaplan RN, Rafii S, Lyden D. Preparing the "soil": the premetastatic niche. Cancer Res. 2006;66(23):11089-93.

15. Aguirre Ghiso JA, Kovalski K, Ossowski L. Tumor dormancy induced by downregulation of urokinase receptor in human carcinoma involves integrin and MAPK signaling. J Cell Biol. 1999;147(1):89-104.

16. Aguirre-Ghiso JA, Liu D, Mignatti A, Kovalski K, Ossowski L. Urokinase receptor and fibronectin regulate the ERK(MAPK) to p38(MAPK) activity ratios that determine carcinoma cell proliferation or dormancy in vivo. Mo Biol Cell. 2001;12(4):863-79.

17. Aguirre-Ghiso JA, Estrada Y, Liu D, Ossowski L. ERK(MAPK) activity as a determinant of tumor growth and dormancy; regulation by p38(SAPK). Cancer Res. 2003;63(7):1684-95.

18. Aguirre-Ghiso JA, Ossowski L, Rosenbaum SK. Green fluorescent protein tagging of extracellular signal-regulated kinase and p38 pathways reveals novel dynamics of pathway activation during primary and metastatic growth. Cancer Res. 2004;64(20):7336-45.

19. Sosa MS, Bragado P, Aguirre-Ghiso JA. Mechanisms of disseminated cancer cell dormancy: an awakening field. Nat Rev Cancer. 2014;14(9):611-22.

20. Hurst RE, Bastian A, Bailey-Downs L, Ihnat MA. Targeting dormant micrometastases: rationale, evidence to date and clinical implications. Ther Adv Med Oncol. 2016;8(2):126-37.

21. Marshall JC, Collins JW, Nakayama J, Horak CE, Liewehr DJ, Steinberg SM, et al. Effect of inhibition of the lysophosphatidic acid receptor 1 on metastasis and metastatic dormancy in breast cancer. J Natl Cancer Inst. 2012;104(17): 1306-19.

22. Almog N, Ma L, Raychowdhury R, Schwager C, Erber R, Short S, et al. Transcriptional switch of dormant tumors to fast-growing angiogenic phenotype. Cancer Res. 2009;69(3):836-44

23. Almog N, Henke V, Flores L, Hlatky L, Kung AL, Wright RD, et al. Prolonged dormancy of human liposarcoma is associated with impaired tumor angiogenesis. FASEB J. 2006;20(7):947-9.

24. Naumov GN, MacDonald IC, Weinmeister PM, Kerkvliet N, Nadkarni KV, Wilson SM, et al. Persistence of solitary mammary carcinoma cells in a secondary site: a possible contributor to dormancy. Cancer Res. 2002;62(7): 2162-8.

25. Heyn C, Ronald JA, Ramadan SS, Snir JA, Barry AM, MacKenzie LT, et al. In vivo MRI of cancer cell fate at the single-cell level in a mouse model of breast cancer metastasis to the brain. Magn Reson Med. 2006;56(5):1001-10.

26. Barkan D, Kleinman H, Simmons JL, Asmussen H, Kamaraju AK, Hoenorhoff $\mathrm{MJ}$, et al. Inhibition of metastatic outgrowth from single dormant tumor cells by targeting the cytoskeleton. Cancer Res. 2008;68(15):6241-50.

27. Marlow R, Honeth G, Lombardi S, Cariati M, Hessey S, Pipili A, et al. A nove model of dormancy for bone metastatic breast cancer cells. Cancer Res. 2013;73(23):6886-99.

28. Ghajar CM, Peinado H, Mori H, Matei IR, Evason KJ, Brazier H, et al. The perivascular niche regulates breast tumor dormancy. Nat Cell Biol. 2013; 15(7):807-17.

29. Liu Y, LV J, Liang X, Yin X, Zhang L, Chen D, et al. Fibrin stiffness mediates dormancy of tumor-repopulating cells via a Cdc42-driven Tet2 epigenetic program. Cancer Res. 2018;78(14):3926-37.

30. El Touny LH, Vieira A, Mendoza A, Khanna C, Hoenerhoff MJ, Green JE. Combined SFKMMEK inhibition prevents metastatic outgrowth of dormant tumor cells. J Clin Invest. 2014;124(1):156-68.

31. Fang JY, Tan S-J, Wu Y-C, Yang Z, Hoang BX, Han B. From competency to dormancy: a 3D model to study cancer cells and drug responsiveness. J Transl Med. 2016;14(1):38.

32. Kassim YL, Al Tawil E, Buquet C, Le Cerf D, PierreVannier J. Three dimensional tumor engineering by co-culture of breast tumor and endothelial cells using a hyaluronic acid hydrogel model. J Clin Exp Oncol. 2017;6(5):1000194.

33. Barkan D, Green JE. An in vitro system to study tumor dormancy and the switch to metastatic growth. J Vis Exp. 2011;54.

34. Keeratichamroen S, Lirdprapamongkol K, Svasti J. Mechanism of ECMinduced dormancy and chemoresistance in A549 human lung carcinoma cells. Oncol Rep. 2018;39(4):1765-74.

35. Barkan D, El Touny LH, Michalowski AM, Smith JA, Chu I, Davis AS, et al. Metastatic growth from dormant cells induced by a col-l-enriched fibrotic environment. Cancer Res. 2010;70(14):5706-16.
36. Ranganathan AC, Adam AP, Zhang L, Aguirre-Ghiso JA. Tumor cell dormancy induced by p38SAPK and ER-stress signaling: an adaptive advantage for metastatic cells? Cancer Biol Ther. 2006;5(7):729-35.

37. Ranganathan AC, Adam AP, Aguirre-Ghiso JA. Opposing roles of mitogenic and stress signaling pathways in the induction of cancer dormancy. Cell Cycle. 2006;5(16):1799-807.

38. Sosa MS, Avivar-Valderas A, Bragado P, Wen HC, Aguirre-Ghiso JA. ERK1/2 and p38alpha/beta signaling in tumor cell quiescence: opportunities to control dormant residual disease. Clin Cancer Res. 2011;17(18):5850-7.

39. Narkhede AA, Shevde LA, Rao SS. Biomimetic strategies to recapitulate organ specific microenvironments for studying breast cancer metastasis. Int J Cancer. 2017;141(6):1091-109.

40. Azarin SM, Yi J, Gower RM, Aguado BA, Sullivan ME, Goodman AG, et al. In vivo capture and label-free detection of early metastatic cells. Nat Commun. 2015;6:8094.

41. Rao SS, Bushnell GG, Azarin SM, Spicer G, Aguado BA, Stoehr JR, et al. Enhanced survival with implantable scaffolds that capture metastatic breast Cancer cells in vivo. Cancer Res. 2016;76(18):5209-18.

42. Aguado BA, Caffe JR, Nanavati D, Rao SS, Bushnell GG, Azarin SM, et al. Extracellular matrix mediators of metastatic cell colonization characterized using scaffold mimics of the pre-metastatic niche. Acta Biomater. 2016;33:13-24.

43. Seib FP, Berry JE, Shiozawa Y, Taichman RS, Kaplan DL. Tissue engineering a surrogate niche for metastatic cancer cells. Biomaterials. 2015;51:313-9.

44. Bersani F, Lee J, Yu M, Morris R, Desai R, Ramaswamy S, et al. Bioengineered implantable scaffolds as a tool to study stromal-derived factors in metastatic cancer models. Cancer Res. 2014;74(24):7229-38.

45. Hesami P, Holzapfel BM, Taubenberger A, Roudier M, Fazli L, Sieh S, et al. A humanized tissue-engineered in vivo model to dissect interactions between human prostate cancer cells and human bone. Clin Exp Metastasis. 2014; 31(4):435-46.

46. Hurst RE, Kyker KD, Bonner RB, Bowditch RD, Hemstreet GP 3rd. Matrixdependent plasticity of the malignant phenotype of bladder cancer cells. Anticancer Res. 2003;23(4):3119-28.

47. Dozmorov MG, Kyker KD, Saban R, Knowlton N, Dozmorov I, Centola MB, et al. Analysis of the interaction of extracellular matrix and phenotype of bladder cancer cells. BMC Cancer. 2006:6:12

48. Hurst RE, Hauser PJ, Kyker KD, Heinlen JE, Hodde JP, Hiles MC, et al. Suppression and activation of the malignant phenotype by extracellular matrix in xenograft models of bladder cancer: a model for tumor cell "dormancy". PLoS One. 2013;8(5):e64181.

49. Hurst RE, Hauser PJ, You Y, Bailey-Downs LC, Bastian A, Matthews SM, et al. Identification of novel drugs to target dormant micrometastases. BMC Cancer. 2015:15:404.

50. Fluegen G, Avivar-Valderas A, Wang Y, Padgen MR, Williams JK, Nobre AR, et al. Phenotypic heterogeneity of disseminated tumour cells is preset by primary tumour hypoxic microenvironments. Nat Cell Biol. 2017;19(2):120-32.

51. Lee HR, Leslie F, Azarin SM. A facile in vitro platform to study cancer cell dormancy under hypoxic microenvironments using $\mathrm{CoCl}(2)$. J Biol Eng. 2018;12:12.

52. Discher DE, Mooney DJ, Zandstra PW. Growth factors, matrices, and forces combine and control stem cells. Science. 2009;324(5935):1673-7.

53. Schrader J, Gordon-Walker TT, Aucott RL, van Deemter M, Quaas A, Walsh S, et al. Matrix stiffness modulates proliferation, chemotherapeutic response, and dormancy in hepatocellular carcinoma cells. Hepatology. 2011;53(4): 1192-205.

54. Preciado JA, Reátegui E, Azarin SM, Lou E, Aksan A. Immobilization platform to induce quiescence in dormancy-capable cancer cells. Technology. 2017; 05(03):129-38.

55. Long TJ, Sprenger CC, Plymate SR, Ratner BD. Prostate cancer xenografts engineered from 3D precision-porous poly(2-hydroxyethyl methacrylate) hydrogels as models for tumorigenesis and dormancy escape. Biomaterials. 2014:35(28):8164-74.

56. Guiro K, Patel SA, Greco SJ, Rameshwar P, Arinzeh TL. Investigating breast Cancer cell behavior using tissue engineering scaffolds. PLoS One. 2015; 10(4):e0118724.

57. Pavan Grandhi TS, Potta T, Nitiyanandan R, Deshpande I, Rege K. Chemomechanically engineered 3D organotypic platforms of bladder cancer dormancy and reactivation. Biomaterials. 2017:142:171-85.

58. Wheeler SE, Clark AM, Taylor DP, Young CL, Pillai VC, Stolz DB, et al. Spontaneous dormancy of metastatic breast cancer cells in an all human liver microphysiologic system. Br J Cancer. 2014;111(12):2342-50. 
59. Khazali AS, Clark AM, Wells A. Inflammatory cytokine IL-8/CXCL8 promotes tumour escape from hepatocyte-induced dormancy. Br J Cancer. 2018; 118(4):566-76.

60. Clark AM, Kumar MP, Wheeler SE, Young CL, Venkataramanan R, Stolz DB, et al. A model of dormant-emergent metastatic breast Cancer progression enabling exploration of biomarker signatures. Mol Cell Proteomics. 2018; 17(4):619-30.

61. Clark AM, Wheeler SE, Young CL, Stockdale L, Shepard Neiman J, Zhao W, et al. A liver microphysiological system of tumor cell dormancy and inflammatory responsiveness is affected by scaffold properties. Lab Chip. 2016;17(1):156-68.

62. Hassell BA, Goyal G, Lee E, Sontheimer-Phelps A, Levy O, Chen CS, et al. Human organ Chip models recapitulate Orthotopic lung Cancer growth, therapeutic responses, and tumor dormancy in vitro. Cell Rep. 2017;21(2): 508-16.

63. Sosnoski DM, Norgard RJ, Grove CD, Foster SJ, Mastro AM. Dormancy and growth of metastatic breast cancer cells in a bone-like microenvironment. Clin Exp Metastasis. 2015;32(4):335-44.

64. Price $\Pi$ T, Burness ML, Sivan A, Warner MJ, Cheng R, Lee CH, et al. Dormant breast cancer micrometastases reside in specific bone marrow niches that regulate their transit to and from bone. Sci Transl Med. 2016;8(340) 340ra73340 ra73.

65. Chiang AC, Massagué J. Molecular basis of metastasis. N Engl J Med. 2008; 359(26):2814-23.

66. Dhurjati R, Liu X, Gay CV, Mastro AM, Vogler EA. Extended-term culture of bone cells in a compartmentalized bioreactor. Tissue Eng. 2006; 12(11):3045-54.

67. Kitamura T, Qian BZ, Pollard JW. Immune cell promotion of metastasis. Nat Rev Immunol. 2015;15(2):73-86.

68. Janssen LME, Ramsay EE, Logsdon CD, Overwijk WW. The immune system in cancer metastasis: friend or foe? J Immunother Cancer. 2017;5(1):79.

69. Romero I, Garrido F, Garcia-Lora AM. Metastases in immune-mediated dormancy: a new opportunity for targeting cancer. Cancer Res. 2014;74(23): 6750-7.

70. He J, Xiong L, Li Q, Lin L, Miao X, Yan S, et al. 3D modeling of cancer stem cell niche. Oncotarget. 2018;9(1):1326-45.

71. Kleffel S, Schatton T. Tumor dormancy and cancer stem cells: two sides of the same coin? Adv Exp Med Biol. 2013;734:145-79.

72. Singh A, Settleman J. EMT, cancer stem cells and drug resistance: an emerging axis of evil in the war on cancer. Oncogene. 2010;29(34):4741-51.

73. Jolly MK, Ware KE, Gilja S, Somarelli JA, Levine H. EMT and MET: necessary or permissive for metastasis? Mol Oncol. 2017;11(7):755-69.

74. Gomis RR, Gawrzak S. Tumor cell dormancy. Mol Oncol. 2017;11(1):62-78.

Ready to submit your research? Choose BMC and benefit from:

- fast, convenient online submission

- thorough peer review by experienced researchers in your field

- rapid publication on acceptance

- support for research data, including large and complex data types

- gold Open Access which fosters wider collaboration and increased citations

- maximum visibility for your research: over $100 \mathrm{M}$ website views per year

At BMC, research is always in progress.

Learn more biomedcentral.com/submissions 